\title{
A comparative study of the characteristics of French Fries produced by deep fat frying and air frying
}

Article

Accepted Version

Teruel, M. d. R., Gordon, M., Linares, M. B., Garrido, M. D., Ahromrit, A. and Niranjan, K. (2015) A comparative study of the characteristics of French Fries produced by deep fat frying and air frying. Journal of Food Science, 80 (2). E349-E358. ISSN 0022-1147 doi: https://doi.org/10.1111/1750-3841.12753 Available at https://centaur.reading.ac.uk/43748/

It is advisable to refer to the publisher's version if you intend to cite from the work. See Guidance on citing.

To link to this article DOI: http://dx.doi.org/10.1111/1750-3841.12753

Publisher: Wiley

All outputs in CentAUR are protected by Intellectual Property Rights law, including copyright law. Copyright and IPR is retained by the creators or other copyright holders. Terms and conditions for use of this material are defined in the End User Agreement.

www.reading.ac.uk/centaur 
Central Archive at the University of Reading

Reading's research outputs online 


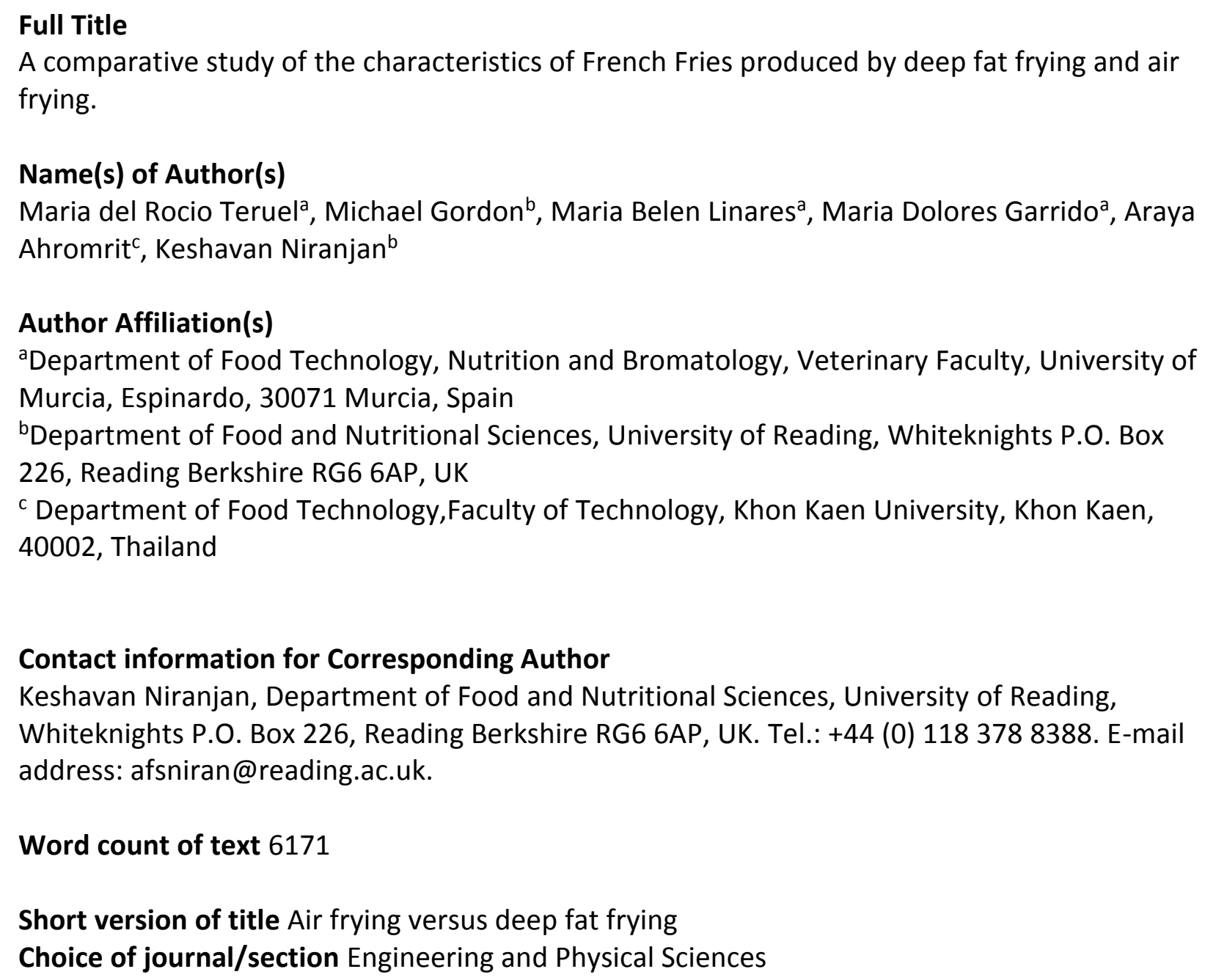


ABSTRACT: Air frying is being projected as an alternative to deep fat frying for producing snacks such as French Fries. In air frying, the raw potato sections are essentially heated in hot air containing fine oil droplets, which dehydrates the potato and attempts to impart the characteristics of traditionally produced French fries, but with a substantially lower level of fat absorbed in the product. The aim of this research is to compare: 1) the process dynamics of air frying with conventional deep fat frying under otherwise similar operating conditions, and 2) the products formed by the two processes in terms of color, texture, microstructure, calorimetric properties and sensory characteristics Although, air frying produced products with a substantially lower fat content but with similar moisture contents and color characteristics, it required much longer processing times, typically 21 minutes in relation to 9 minutes in the case of deep fat frying. The slower evolution of temperature also resulted in lower rates of moisture loss and color development reactions. DSC studies revealed that the extent of starch gelatinization was also lower in the case of air fried product. In addition, the two types of frying also resulted in products having significantly different texture and sensory characteristics.

Keywords: Air frying, deep fat frying, French fries, oil uptake, sensory evaluation;

Practical Application: Despite air fryers being available in our markets, systematic comparisons of the quality and sensory characteristics of products such as French fries produced by air frying and deep fat frying are not available. This study shows that the colour of air fried products can be similar to deep fat fried product, but the texture is harder, and mouth feel and appearance are dryer - more akin to puffed/baked products. This study will advance our quest to develop truly competing alternatives to deep fat frying which yield products having the same mouth-feel and eating experience. 


\section{Introduction}

Frying is essentially a dehydration process involving rapid heat and mass transfer in food immersed in hot oil, which leads to a succession of physical and chemical changes in the product (Tarmizi and Ismail 2008; Andrés-Bello and others 2011; Dueik and Bouchon 2011). Frying is extensively employed in domestic as well as industrial practice, due to its ability to create unique sensory properties, including texture, flavour and appearance, which make the food more palatable and desirable (Dana and Saguy 2006). Furthermore, its operational simplicity in the context of commercial practice, convenience, and economic viability, has resulted in extensive sales of a large variety of fried products (Mehta and Swinburn 2001). Despite, the many studies correlating fried product consumption with increased health risks (Krokida and others 2001; Mariscal and Bouchon 2008), and increasing consumer awareness of this relationship (Mariscal and Bouchon 2008), there is no sign to suggest that we will give up eating fried products (Dana and Saguy 2006; Tarmizi and Ismail 2008; Sayon-Orea and other 2013). These issues have prompted the fried product industry to search for ways and means to produce healthier products without compromising on the desirable appearance, texture, flavour and taste attributes (Garayo and Moreira 2002; Fan and others 2005; Da Silva and Moreira 2008; Mariscal and Bouchon 2008; Andrés-Bello and others 2011; Andrés and others 2013).

One such process is hot air frying, which aims to produce a "fried product" by sparging, essentially, hot air around the material instead of immersing it in hot oil. A variety of proprietary air fryer designs are currently available in the market, which create the frying effect by bringing direct contact between a fine mist of oil droplets in hot air and the product, inside 
a chamber. Most designs provide for extremely high heat transfer rates uniformly between air and the product being fried. Some achieve this simply with a built-in air blower, while others also couple high convective rates with radiative heat transfer. A number of manufacturers also claim that the shape of the chamber in which air and product are being contacted is profiled in such a way that air velocities are significantly higher than in typical ovens (Erickson 1989). Moreover, the air is also distributed more uniformly through the product, which minimizes variations in product quality. A schematic of a typical air fryer is shown in Fig. 1. The product gets dehydrated in the process and a crust, typically associated with frying, gradually appears on the product. Oil application could be done before or during the process to lightly coat the food product, in order to provide the taste, texture and appearance typical of fried products. The amount of oil used is significantly lower than in deep oil frying giving, as a result, very low fat products (Andrés and others 2013). To date, there is only a scientific publication about hot air frying. Andrés and others (2013) analyzed the kinetics of mass transfer and volume changes in hot air frying and deep-oil frying at the same temperature $\left(180^{\circ} \mathrm{C}\right)$ and concluded that both are affected by medium type. Heat transfer was slower when the fluid phase is air than when it is oil, due to lower heat transfer coefficient of air. Moreover, they also observed that product mass losses in air frying were higher than in deep frying, because the water lost during air frying was not offset by any significant oil uptake. Unfortunately, this paper makes little or no reference to the quality and sensory parameters of the product, and this is a major knowledge gap. In the present work, we have aimed to draw a comparison between: 1) process parameters of air frying and hot air frying - such as moisture content time profile, product temperature versus time profile and product oil content versus time profile, and 2) product 
characteristics yielded by the two frying methods, which include starch gelatinization profile, microstructure using SEM as well as sensory characteristics. This detailed comparison has been drawn by holding the same frying medium temperature in both cases, i.e. $180{ }^{\circ} \mathrm{C}$. Further, the product characteristics mentioned above, including sensory analysis, have been compared after fixing the final product moisture content at a value that consumers normally consume (91.7 \pm 6.03 g water/ $100 \mathrm{~g}$ defatted dry matter), which also helps us to evaluate whether air frying can produce a true alternative to traditional frying.

\section{Materials and Methods}

\section{Raw materials}

Maris Piper potatoes packaged in polyethylene bags and sunflower oil were purchased from a local supermarket (Morrisons, Reading, UK), and stored in a refrigerator at $4 \stackrel{\circ}{ } \mathrm{C}$.

\section{Frying equipment used}

Commercial deep oil frying (model: 45470, Morphyrichards) with a nominal power: 2,000 W) and hot air frying equipment (model: AH-9000 Viva Collection Airfryer HD9220/40, Philips) with a nominal power: $1,300 \mathrm{~W}$.

\section{Sample preparation}

The samples were prepared following the methodology described by Tarmizi and Niranjan (2010). Potatoes ranging in moisture content between $445.37 \pm 107.77 \mathrm{~g}$ water/100 g dry matter were selected for this study. The potatoes were taken out from the fridge in which they were stored at least $12 \mathrm{~h}$ before being used in experiments, then washed, peeled and manually 
115 cut into strips $(9 \times 9 \times 30 \mathrm{~mm})$. The strips were soaked in running water for $1 \mathrm{~min}$ to eliminate

116 occluded starch and blotted using tissue paper.

\section{Frying protocol}

118 The frying methodology, described by Andrés and others (2013), was used in this study. In the

119 case of deep fat frying, about $100 \mathrm{~g}$ of potato strips were immersed in $2 \mathrm{~L}$ of oil to give a

120 product to oil ratio of 1:20 (w/v) which was deemed by Andrés and others (2013) to be

121 sufficient to avoid major changes occurring in terms of product-to-oil ratio, oil composition and

122 temperature. In the case of hot air frying experiments, $0.45 \mathrm{~g}$ of oil per $100 \mathrm{~g}$ of potatoes strips,

123 was added into the air chamber.

124 The potato strips were only introduced into the oil in the case of deep fat frying or into the hot

125 air frying chamber in the case of air frying, after an operating temperature of $180^{\circ} \mathrm{C}$ was

126 reached, the temperature being confirmed by thermocouples located at the bottom of both

127 frying equipment. Samples were removed from the frying equipment at 3 min intervals, for up

128 to a maximum of 30 mins, and subjected to physico-chemical analysis.

129 Transient analyses of French fries

130 Proximate composition

131 Samples were analysed according to American Oil Chemists' Society official methods, also

132 described by Tarmizi and Niranjan (2010).

133 Moisture content: The moisture content was determined by taking three homogenized samples

134 of $10 \mathrm{~g}$ collected at each processing time, and drying these for 48 hours at 105 ㅇ $\mathrm{C}$ in the

135 convection oven (Weiss-Gallenkamp, Loughborough, U.K.) to obtain a constant weight. 
Oil content determination: The total fat content of three dried samples $(5 \mathrm{~g})$ collected at a given processing time was measured. The dried samples were ground using a mortar and transferred to a single-thickness cellulose extraction thimble (Fisher Scientific UK Ltd, Loughboroug, UK). A dried and weighed 250-mL round-bottom flask (Quickfit-BDH, Poole, U.K.) was filled with 150 $\mathrm{mL}$ of petroleum ether (Fisher Scientific UK Ltd, Loughboroug, UK), and oil was extracted gravimetrically using a Soxhlet extraction system (Quickfit-BDH) for $4 \mathrm{~h}$. The solvent was then removed by rotary evaporation (Rotavapor RE 111, Büchi Labortechnik AG, Flawil, Switzerland) under vacuum of 380 to $510 \mathrm{mmHg}$ at $50^{\circ} \mathrm{C}$. The flask containing oil was dried to constant weight at $105{ }^{\circ} \mathrm{C}$ using the same convection oven described above (Weiss-Gallenkamp, Loughborough, U.K.). The oil content was expressed as g oil/100 g defatted dry matter. Color

The color of the potato French fries was measured using a reflectance colorimeter (HunterLab CT-1100 ColorQUEST, Reston, VA). According to the CIE LAB system, Lightness ( $\left.{ }^{*}\right)$, green-red chromacity $\left(a^{*}\right)$, and blue-yellow chromacity $\left(b^{*}\right)$ were measured. The illuminant used was D 65 and the colorimeter was standardized using a cylindrical light trap (black), followed by standard white and grey calibration plates. All measurements were undertaken in triplicate.

\section{Texture}

Texture measurements were made with Brookfield CT3 Texture fitted with $25 \mathrm{~kg}$ load cell. Data collection and analysis was accomplished by using electronic Texture Pro CT software. A single cycle puncture test was performed using a cylindrical flat-end punch ( $2 \mathrm{~mm}$ diameter probe) by fixing the test speed at $4.6 \mathrm{~mm} / \mathrm{s}$; the punch was allowed to travel into the samples for: $2 \mathrm{~mm}$ 
157 (covering the crust region) and $6 \mathrm{~mm}$ (which covered the core). Six samples were measured and punctured at 2 random positions for each processing time. Analyses of the final product (i.e. ready to consume)

160 Although the above analyses were carried out over an extended time scale, which was much

161 longer than what will be used in practice, the final product was defined in accordance with the 162 quality control criteria set by frying industry, which stipulates that the moisture content of the

163 ideal product must be in the range between $38 \%$ and $45 \%$ on a wet weight basis (Matthäus and

164 others 2004). The moisture and oil contents, color and texture of the final product were

165 determined as above. In addition, SEM, DSC and sensory analyses were also carried out on the 166 final product.

167 Scanning electron microscopy (SEM)

168 Sections taken from the core and crust regions of the product were freeze-dried and their

169 fractured surface was examined and photographed using a scanning electron microscope (FEI

170 Quanta FEG 600 with a Quorum PP2000T Cryo Stage, Eindhoven, Netherlands) at different

171 magnifications, and representative images were chosen.

\section{Differential scanning calorimetry (DSC)}

173 The method of Steeneken and Woortman (2009) was used. Heating scans were performed on core samples of French fries by employing a Perkin Elmer DSC 200, by heating from 20 to $210^{\circ} \mathrm{C}$ at $10^{\circ} \mathrm{C} / \mathrm{min}$ followed by cooling to $20^{\circ} \mathrm{C}$ at $200^{\circ} \mathrm{C} / \mathrm{min}$.

176 Sensory analysis

177 For the sensory analysis, all evaluations were conducted in individual booths which contained the instructions for the evaluation procedure. The tasting room for sensory evaluation was air- 
192 level.

193 level.

conditioned and free of disturbing factors. Samples were fried in a commercial deep fat fryer (model: 45470, Morphyrichards) at 180ㄷ for 9 minutes and in a commercial air fryer (AH-9000 Viva Collection Airfryer HD9220/40, Philips) at 180ㄷ for 21 minutes. Samples were obtained, and immediately after, were presented to the panelists.

The panelists were trained according to ISO 8586 (2012). The training program consisted of three sessions aiming to develop sensory descriptors and ensure competent usage of these by the panel. For each sample the panelists registered the perceived intensities of each of the attributes. These attributes were individually recorded using an unstructured scale of $100 \mathrm{~mm}$, and the data sets checked by ANOVA. Mineral water and bread were provided for mouth rinsing between samples.

\section{Statistical analysis}

The statistical analysis of the data was conducted using statistical package SPSS 15.0 (Statistical Package for the Social Science for Windows). Statistical significance was expressed at p b 0.05

\section{Results and Discussion}

\section{Analyses of French fries during the Frying Processes}

\section{Temperature profile}

The temperature of French fries, measured at a point, more or less, near the centre, under different frying conditions (deep-fat frying and air frying) is presented in Figure 2. The deep-fat fried samples behaved in a manner similar to the one described in earlier work (Budžaki and Seruga 2005; Farinu and Baik 2008; Mir-Bel and others 2012). The initial temperature increased, almost linearly with time, until it reached the boiling point of water ( $100 \circ \mathrm{C})$. The 
201 temperature then increased gradually for a period of time, before increasing more sharply. The

202 air fried samples also showed the same initial trend, i.e. temperature increasing linearly up to 203 the boiling point of water, but at a significantly slower rate than deep-fat frying. The oil fried 204 sample took 1.5 minutes to reach the boiling point of water, whereas the air fried sample took 205 nearly 5.5 minutes. A second difference between oil frying and air frying is that the 206 temperature, in the case of the latter process, remains, more or less, constant at the boiling 207 point of water till the end of the process, and the gradual, but significant, increase in 208 temperature above $100^{\circ} \mathrm{C}$ observed in the case of deep oil frying is not evident. Based on the 209 times taken for the product centre to reach the boiling point of water, it can be estimated that 210 the heat flux in the case of oil frying is 3.7 times greater than in the case of air frying, which 211 seems to provide enough energy in the form of latent heat as well as sensible heat. The post 212 boiling heat transfer is accompanied by physicochemical changes occurring such as: gelation of 213 starches, increase in the thickness of superficial crust and reduction in the rate of steam 214 release from the product (Mir-Bel and others 2012).

\section{Moisture and oil content}

Frying process normally implies a series of complex mass transfer processes between the food

217 and fluid phase giving, as a result, two counter current-fluxes: a water/steam flow from the

218 food to the hot oil and an oil inlet into the food (Ziaiifar and other 2008; Krotida and others

219 2000; Andrés 2013; Kalogianni and Popastergiadis 2014), although such simplistic explanations

220 have been questioned (Bouchon and Pyle 2005).

221 The variation of moisture content (expressed as $\mathrm{g} / 100 \mathrm{~g}$ defatted dry matter) with time for 222 different frying conditions is shown in Figure 3. As expected, the moisture decreases with 
223 frying time $(P<0.05)$ for both deep-fat as well as air frying. The mechanism of water loss

224 during frying has been interpreted previously as a dehydration process (Mir-Bel and others

225 2012; Bingol and others 2014). It is clear from Figure 3 that the moisture content decreases

226 more rapidly in deep-fat frying than air frying $(P<0.05)$. These results are consistent with

227 higher heat flux observed in the case of deep-fat frying and are also in agreement with Andrés

228 and others (2013) who compared moisture loss kinetics between the two frying methods.

229 Figure 4 shows fat content variation with time in of the two frying process. The values varied

230 between $0.37-1.12 \mathrm{~g} / 100 \mathrm{~g}$ defatted dry matter for samples processed by air frying, and

231 between 5.63-13.77 g/100g defatted dry matter for deep fat fried samples. The differences

232 between the oil contents may be attributed to the "frying medium" surrounding the products:

233 hot oil in the case of deep fat frying, and a mist of oil droplet in air in the case of deep fat

234 frying. This observation is also in agreement with the findings of Andrés and others (2013) who

235 showed that the main difference between the two types of frying is the final fat content and

236 these differences are due to the type of frying medium employed. In the case of deep fat

237 frying, it is known that the oil absorption (64-90\% of the total oil absorbed) predominantly

238 occurs at the end of frying, due to the condensation of water vapor inside product caused by

239 the fall in temperature below the boiling point of water, which creates a suction pressure

240 gradient between the surface and the inner structure of the product (Mellema 2003; Saguy and

241 Dana 2003; Dana and Saguy 2006; Ziaiifar and others 2008; Mir-Bel and others 2009; Tarmizi

242 and Niranjan 2010). Deep-fat frying is undertaken in oil (20 g of oil per gram of potatoes),

243 whereas air-frying samples are mixed with a small oil amount before "frying" ( $0.003 \mathrm{~g}$ of oil by 
244 gram of potatoes). This implies that, in the case of the latter process, a limited amount of oil is

245 in contact with the sample surface and therefore oil absorption is limited.

246 Color

247 The color of the fried potatoes is one of the most significant quality factors determining

248 acceptance (Korkida and others 2001). Instrumental color coordinates (CIELab) for both types

249 of French fries are shown in Figure 5.

250 As expected, $L^{*}$ decreased with frying time in the two processes whereas $a^{*}$ and $b^{*}$ increased

$251(P<0.05)$. This is consistent with the potatoes turning darker and more red-yellow as described

252 by Nourian and Ramaswamy (2003) and Romani and others (2009a, b). The characteristic color

253 of French fried potatoes essentially result from the Maillard reaction (non-enzymatic browning)

254 involving reducing sugars and amino acids (Nouiuan and Ramaswamy 2003; Pathare and others

255 2013).

256 It is also clear from Figures 5 that a* and b* drop initially, attain a minimum value,-and then

257 increase progressively before leveling off around the same values for both types of products. A

258 closer analysis of the figures also shows that the minimum values of $a^{*}$ and $b^{*}$ are attained

259 much more rapidly in the case of deep fat frying $(P<0.05)$ The rapid evolution of colour is

260 consistent with the higher rates of temperature rise observed in the case of deep fat frying

261 (Figure 2). Baik and Mittal (2003), Pedreschi and others (2005) and Ngadi and others (2007)

262 and Pathare and others (2013) reported that the non-enzymatic browning reactions are highly

263 temperature dependant. Thus, air frying process can potentially achieve the characteristic

264 color of deep fat fried French fries but requires significantly longer processing time.

265 Texture 
The kinetics of textural changes occurring in the two types of products was studied using a compression test. Table 1 shows hardness work $(\mathrm{mJ})$ for the probe to penetrate the surface ( 2 $\mathrm{mm})$ and core $(6 \mathrm{~mm})$ of samples.

Moyano and others (2007) and Pedreschi and Moyano (2005) observed that heating of potato tissue causes drastic physical, chemical, and structural changes, which could be divided into two stages: the tissue softening during the first few minutes of frying followed by crust formation and subsequent hardening. The same trend was observed in the present study for deep fat, as well as, air fried products. Table 1 shows the hardness work to decrease initially. The evaluation of texture parameter (hardness work) at $2 \mathrm{~mm}$ and $6 \mathrm{~mm}$ allowed studying the crust development and the modifications in product core, respectively. The initial stage of frying resembles a cooking process when a part of the starch gelatinizes and the lamellar media solubilizes at temperatures of around 60 to 70 ㅇ C (Moyano and others 2007). The softening phase of the tissue, at the surface as well as core, was much faster in deep fat frying $(p<0.05)$ which required only 3 minutes (105으) to be completely softened, compared to 6 minutes $\left(100^{\circ} \mathrm{C}\right)$ required for air fried samples.

The second stage is characterized by the development of a porous dried region and an overheated region which is generically called "crust". This region is result of a vaporization front located close to the heat exchange surface which progressively moves towards the product center with the frying time. Miranda and Aguilera (2006) showed that the exposure of potato products to temperatures above $100^{\circ} \mathrm{C}$, such as the temperatures encountered during frying, causes starch granules and cells located on the surface to become dehydrated and form 
an external crust, which makes the product crispy. Both processes showed increase in hardness work values for the crust and core regions with time $(P>0.05)$.

With regard to the effect of frying methods, in general no differences were observed between the two frying methods for crust region at different frying times. However in the case of the core region, the air fried samples showed higher hardness work values $(P<0.05)$ than the deep fat fried samples. These differences in core texture may be due to a smaller degree of gelatinization occurring in air fried samples, associated with the prevalence of lower

294 temperatures inside the product.

As evident in Table 1, with time, the evaporation continues until the products are completely dry, in both processes, and the hardness work converge to more or less identical values at very consumer acceptability of the product.

The quality parameters of the final product, withdrawn at this end point, i.e. the products which are meant to be consumed, are discussed below. In terms of texture data shown in Table 1 , it is clear that both products have different texture characteristics in both the regions: crust $11.49 \mathrm{~mJ}(P<0.05 ; P<0.001)$.

Analyses of the final product deemed to be fit for consumption and core. Air fried samples (21minutes) had hardness work values about 1.38 and $7.29 \mathrm{~mJ}$ for crust and core respectively, while that deep fat fried samples (9 minutes) were about 4.23 and 
others 2006; Romani and others 2008). To meet this criterion the samples used in this study were processed for 9 minutes in the case of deep-fat frying and for 21 minutes in the case of

311 air frying, both at $180^{\circ} \mathrm{C}$. SEM, DSC and sensory analyses were undertaken to compare the two 312 products.

\section{SEM and DSC analyses}

314 Figure 6 show the microstructure of the raw and fried potato chips. Figure $6(a-b)$ shows the 315 cross section of raw potato chips. The core of the chips contain non-deformed flesh cells with 316 starch granules, while the outer surface reveals mechanical damage of cells caused by the 317 cutting process; these results are similar to the ones described by Lisińska and Golubowska 318 (2005).

319 When we compare the raw potato tissue consisting of cells appearing pentagonal/hexagonal in shape (Figure 6 a-b) with the tissue resulting after "frying" (Figure $6 c-h$ ), irreversible changes can be seen and two particularly clear areas appear: crust and core. Aguilera and others (2001) and Pedreschi and Aguilera (2002) postulated that cells in the crust of fried potato tended to change their shape while shrinking, and their walls became wrinkled and convoluted around dehydrated gelatinised starch; there was however, little or no rupture evident. The crust of air

325 fired samples (Figure $6 \mathrm{f}$ and $\mathrm{h}$ ) showed higher empty spaces and smaller cells than deep-fat fried samples, because the temperatures and rates of water evaporation were different in the two process; moreover, any empty spaces formed during deep fat frying would be filled with oil. On the other hand, in both products, starch swelling mainly occurred in the core region, which is a result of grain hydration and gelatinisation to form an amylase and amilopectin reticulum which completely fills the cellular lumen (García-Segovia and others 2008), although 
331 this process occurred to a greater degree in deep fat fried samples (Figure $6 \mathrm{~d}$ ) than air fried

sample (Figure $6 \mathrm{~g}$ ). Similar results were noted for the DSC analyses given in Figure 7. Both process showed higher gelatinization temperature and weaker endotherms than raw samples, which indicates the modification of starch structure due to gelatinization process (Garzón 2006; Liu and others 2009). Furthermore, deep-fat fried samples have a lower value of the enthalpy of gelatinization $(\Delta \mathrm{H})$ than air fried samples. According to Bello (2009) lower values of enthalpy indicates a higher proportion of gelatinized starch. Thus, a key difference between air fired and deep fat fried products is the higher extent of gelatinization occurring in the latter. Sensory analyses

A panel evaluated appearance, odor, mouthfeel, taste, flavor and after effects of products obtained by both types processes, based on 31 descriptors (Table 2). There were statistically significant differences found for 22 of the 31 attributes $(P<0.05)$ used, which indicates major difference in the perceived product characteristics. It may be noted that the air fired product was processed for 21 minutes, whereas the deep fat fried product was processed for 9 minutes. Under these conditions, both products had average moisture content about $45 \%$. In terms of appearance, the extent of brownness and evenness of cooking were not significantly different between air fried and deep fat fried samples, which is also in agreement with instrumental color measurement. However, air fried samples stood out in terms of appearing puffed and dry, when compared with deep-fat fried samples which also highlighted oiliness attributes $(P<0.05)$; the SEM images shown in Figure 6 are consistent with these sensory observations. With regard to odor, the deep-fat fried product gave a fried smell and flavor, while the air fried samples give what was described as "jacket potato smell" $(P<0.05)$. 
353 In the same way, the after effects attributes only show differences in terms of the deep fat

354 fried product giving a oily mouth coating and greasy fingers. The skin mouth feel was smoother

355 and it felt tough in the case of air fried samples $(P<0.05)$ which is also consistent with the

356 texture test that showed higher values of hardness work for air fried samples than deep-fat

357 fried samples. However, the crispness was similar $(P>0.05)$. In traditional deep-fat frying, oil

358 migrates to intracellular spaces formed by cell wall shrinkage and water evaporation (Costa Rui

359 and others 2001), resulting in a more oily mouth feel $(P<0.001)$. On the other hand, in air fried

360 samples, these spaces remain void and gave a desiccated mouth feel. The floury mouthfeel and

361 earthy flavor were significantly higher in deep-fat fried samples. The mealiness sensation in

362 potatoes is associated with a greater volume of the gelatinized starch filled up in their cells

363 (Bordoloi and others 2012). These observations are also supported by DSC and SEM

364 measurement (Figure 6 and 7).

365 In general, the QDA results indicate that sensory characteristics of the products obtained from

366 the two processes are significantly different, and the key differences will be summarized

367 below.

\section{Key appearance differences between air fried and deep fat fried products}

369 The external appearance of the samples is shown in Figure 8. The color of air fried and deep fat

370 fried products may not be significantly different, however, the visual presence of fat in deep-

371 fat fried product is amply evident. Another major difference between samples fried in air and

372 oil is the structure of the products formed. Visual observations indicate that deep-fat fried

373 samples have a surface crust structure which is dry, crisp and thick. This is the result of the high

374 temperatures being reached rapidly at the product surface which causes intense local water 
evaporation that impedes gelatinization of the starch in the region. In the case of air fried product, the water evaporates much more slowly causing the surface crust to be thinner, homogeneous and without irregularities, which gives a perceptible difference in mouth feel. The visual observations of the crust also showed that air-fried samples expanded to a greater extent and contained regular pore distribution in core region in contrast to deep fat fried samples. During cooling too, the air-fried samples showed crust shrinkage, which was not observed in the deep fat fried product. Higher crust shrinkage during cooling is indeed a feature of air fried product, which does not seem to happen to the same extent in the case of deep fat fried product. This is most probably because crust cooling of air fried product occurs with concomitant steam condensation that leaves voids in the crust causing it to collapse. In contrast, the presence of oil in the crust of deep fried products minimizes crust collapse. As far as the core is concerned, both products showed gelatinized appearance, although the extent of gelatinization was higher in the deep fat fried product.

\section{Conclusion}

The present study shows that the oil content of French fries having similar moisture content and color was significantly lower when the product is air fried: the values were $5.63 \mathrm{~g} \mathrm{oil} / 100 \mathrm{~g}$ defatted dry matter for deep-oil frying and $1.12 \mathrm{~g}$ oil/100 g defatted dry matter for air frying.

On the other hand, the evolution of temperature, moisture content, and color were significantly slower in the case of air frying than deep-fat frying. As a consequence, longer cooking times are required in the case of air frying. 
395 The final product evaluation by SEM and DSC analyses showed that air fried samples had a

396 lower degree of gelatinization than deep-fat fried samples, which may explain the differences

397 found between texture and sensorial characteristics of the two products.

398 Overall, air frying process permits the manufacture of lower fat content products, though these

399 products have different sensory characteristics.

400 Author Contributions

401 MR. Teruel undertook most of the experimental work presented in this paper, compiled the 402 data and did the statistical analysis. Initial problem identification and some of the experimental 403 procedures were set up by Araya Ahromrit. K. Niranjan, M. Gordon, MB. Linares, MD. Garrido 404 supervised and organized the study.

405 K. Niranjan and MR. Teruel predominantly interpreted the results and drafted the manuscript 406 with help from other authors.

\section{$407 \quad$ References}

408 Aguilera JM, Cadoche L, López C, Gutierrez G. 2001. Microstructural changes of potato cells and 409 starch granules heated in oil. Food Res Int 34(10):939-947.

410 Andrés A, Arguelles Á, Castelló ML, Heredia A. 2013. Mass transfer and volume changes in 411 French fries during air frying. Food Bioprocess Technol 6(8):1917-1924.

412 Andrés-Bello A, García-Segovia P, Martínez-Monzó J. 2011. Vacuum frying: An alternative to 413 obtain high-quality dried products. Food Eng Rev 3(2): 63-78.

414 Baik OD, Mittal GS. 2003. Determination and modeling of thermal properties of tofu. Int J Food 415 Prop 6(1):9-24. 
Bello MO. 2009. Procesamiento hidrotérmico de arroz cáscara: Efecto de las condiciones de hidratación y cocción en el remdimiento, textura y propiedades térmicas del grano elaborado. Doctoral dissertation, Universidad de Buenos Aires, Aregentina.

Bingol G, Wang B, Zhang A, Pan Z, McHugh TH. 2014. Comparison of water and infrared blanching methods for processing performance and final product quality of French fries. J Food Eng 121:135-142.

Bordoloi A, Kaur L, Singh J. 2012. Parenchyma cell microstructure and textural characteristics of raw and cooked potatoes. Food Chem 133(4):1092-1100.

Bouchon P, Pyle DL. 2005. Modelling oil absorption during post-frying cooling: I: model development. Food and Bioprod Process 83(4):253-260.

Budžaki S, Šeruga B. 2005. Determination of convective heat transfer coefficient during frying of potato dough. J Food Eng 66(3):307-314.

Costa RM, Oliveira FA, Boutcheva G. 2001. Structural changes and shrinkage of potato during frying. Int J Food Sci Technol 36(1):11-23.

Da Silva PF, Moreira RG .2008. Vacuum frying of high-quality fruit and vegetable-based snacks. LWT-Food Sci Technol 41(10):1758-1767.

Dana D, Saguy IS. 2006. Review: mechanism of oil uptake during deep-fat frying and the surfactant effect-theory and myth. Adv Colloid Interface Sci 128:267-272.

Dueik V, Bouchon P. 2011. Vacuum frying as a route to produce novel snacks with desired quality attributes according to new health trends. J Food Sci 76(2):E188-E195. 
Erickson CS. 1989. U.S. Patent No. 4,817,509. Washington, DC: U.S. Patent and Trademark

437 Office.

438 Fan L, Zhang M, Mujumdar A. 2005. Vacuum frying of carrot chips. Drying Technol 23:645-656.

439 Farinu A, Baik OD. 2008. Convective mass transfer coefficients in finite element simulations of

440 deep fat frying of sweetpotato. J Food Eng 89(2):187-194.

441 Garayo J, Moreira RG. 2002. Vacuum frying of potato chips. J Food Eng 55(2):181-91.

442 García-Segovia P, Andrés-Bello A, Martínez-Monzó J. 2008. Textural properties of potatoes

443 (Solanum tuberosum/ L., cv. Monalisa) as affected by different cooking processes. J Food Eng

$444 \quad 88(1): 28-35$

445 Garzón MDL. 2006. Almidón retrogradado para uso en compresión directa. Il. Compactación de 446 almidón de chayote retrogradado. Revista Mexicana de Ciencias Farmacéuticas 37(3):29-39.

447 Gökmen V, Palazoğlu TK, Şenyuva HZ. 2006. Relation between the acrylamide formation and 448 time-temperature history of surface and core regions of French fries. J Food Eng 77(4):972449976. International Standards Organization - ISO. 2012. Sensory analysis -- General guidelines for the 451 selection, training and monitoring of selected assessors and expert sensory assessors, ISO 452 8586. Geneva, Switzerland: The International Organization for Standardization

453 Kalogianni EP, Papastergiadis E. 2014. Crust pore characteristics and their development during 454 frying of French-fries. J Food Eng 120:175-182. quality of French fries. J Food Eng 49(4):347-354. 
Krokida MK, Oreopoulou V, Maroulis ZB. 2000. Water loss and oil uptake as a function of frying time. J Food Eng 44(1):39-46.

Lisińska G, Gołubowska G. 2005. Structural changes of potato tissue during French fries production. Food chem 93(4):681-687.

Liu H, Yu L, Dean K, Simon G, Petinakis E, Chen L. 2009. Starch gelatinization under pressure studied by high pressure DSC. Carbohydr polym 75(3):395-400.

Mariscal M, Bouchon P. 2008. Comparison between atmospheric and vacuum frying of apple slices. Food Chem 107(4):1561-1569.

Matthäus B, Haase NU, Vosmann K. 2004. Factors affecting the concentration of acrylamide during deep-fat frying of potatoes. Eur J Lipid Sci Technol 106(11):793-801.

Mehta U, Swinburn B. 2001. A review of factors affecting fat absorption in hot chips. Crit Rev Food Sci Nutr 41(2):133-154.

Mellema M. 2003. Mechanism and reduction of fat uptake in deep-fat fried foods. Trends Food Sci Tech 14(9):364-373.

Miranda ML, Aguilera JM. 2006. Structure and texture properties of fried potato products. Food Rev Int 22(2):173-201.

Mir-Bel J, Oria R, Salvador ML. 2009. Influence of the vacuum break conditions on oil uptake during potato post-frying cooling. J Food Eng 95(3):416-422.

Mir-Bel J, Oria R, Salvador ML. 2012. Influence of temperature on heat transfer coefficient during moderate vacuum deep-fat frying. J Food Eng 113(2):167-176. 
Moyano PC, Troncoso E, Pedreschi F. 2007. Modeling texture kinetics during thermal processing of potato products. J Food Sci 72(2):E102-E107.

Ngadi M, Li Y, Oluka S. 2007. Quality changes in chicken nuggets fried in oils with different degrees of hydrogenatation. LWT-Food Sci Technol 40(10):1784-1791.

Nourian F, Ramaswamy HS. 2003. Kinetics of quality change during cooking and frying of potatoes: Part II. Color. J Food Process Eng 26(4):395-411.

Pathare PB, Opara UL, AI-Said FAJ. 2013. Colour measurement and analysis in fresh and processed foods: a review. Food Bioprocess Technol 6(1):36-60.

Pedreschi F, Aguilera JM. 2002. Some changes in potato chips during frying observed by confocal laser scanning microscopy (CLSM). Food Sci Technol Int 8(4):197-201.

Pedreschi F, Moyano P, Kaack K, Granby K. 2005. Color changes and acrylamide formation in fried potato slices. Food Res Int 38(1):1-9.

Pedreschi F, Moyano P. 2005. Oil uptake and texture development in fried potato slices. J Food Eng 70(4):557-563.

Romani S, Bacchiocca M, Rocculi P, Dalla Rosa M. 2008. Effect of frying time on acrylamide content and quality aspects of French fries. Eur Food Res Technol 226(3):555-560.

Romani S, Bacchiocca M, Rocculi P, Dalla Rosa M. 2009a. Influence of frying conditions on acrylamide content and other quality characteristics of French fries. J Food Compos Anal 22(6):582-588.

Romani S, Rocculi P, Mendoza F, Dalla Rosa M. 2009b. Image characterization of potato chip appearance during frying. J Food Eng 93(4):487-494. 
Saguy IS, Dana D. 2003. Integrated approach to deep fat frying: engineering, nutrition, health and consumer aspects. J Food Eng 56(2):143-152.

Sayon-Orea C, Bes-Rastrollo M, Basterra-Gortari FJ, Beunza JJ, Guallar-Castillon P, De la FuenteArrillaga C, Martinez-Gonzalez MA. 2013. Consumption of fried foods and weight gain in a Mediterranean cohort: the SUN project. Nutr Metab Cardiovasc Dis 23(2):144-150.

Steeneken PA, Woortman AJ. 2009. Identification of the thermal transitions in potato starch at a low water content as studied by preparative DSC. Carbohydrate polymers 77(2):288-292.

Tarmizi AHA, Ismail R. 2008. Comparison of the frying stability of standard palm olein and special quality palm olein. J Am Oil Chem Soc 85(3):245-251.

Tarmizi AHA, Niranjan K. 2010. The possibility of lowering oil content of potato chips by combining atmospheric frying with postfrying vacuum application. J Food Sci 75(9):E572-E579.

Ziaiifar AM, Achir N, Courtois F, Trezzani I, Trystram G. 2008. Review of mechanisms, conditions, and factors involved in the oil uptake phenomenon during the deep-fat frying process. Int J Food Sci Technol 43(8):1410-1423. 


\begin{tabular}{|c|c|c|c|c|c|c|c|c|c|c|c|}
\hline & \multicolumn{11}{|c|}{ Time (minutes) } \\
\hline & 0 & 3 & 6 & 9 & 12 & 15 & 18 & 21 & 24 & 27 & 30 \\
\hline \multicolumn{12}{|c|}{$2 \mathrm{~mm}$} \\
\hline Deep-fat & $16,84 \pm 0,55^{c}$ & $1,26 \pm 0,52^{a, y}$ & $1,28 \pm 0,92^{a}$ & $1,38 \pm 1,26^{a}$ & $2,26 \pm 1,41^{\mathrm{a}}$ & $2,49 \pm 1,19^{a}$ & $1,84 \pm 1,77^{a}$ & $5,41 \pm 3,56^{a}$ & $3,10 \pm 2,53^{a}$ & $10,32 \pm 6,95^{b}$ & $14,93 \pm 6,11^{b c, z}$ \\
\hline Air & $16,84 \pm 0,55^{d}$ & $10,18 \pm 3,80^{\mathrm{bc}, \mathrm{z}}$ & $2,03 \pm 0,71^{a}$ & $1,61 \pm 1,03^{a}$ & $2,06 \pm 0,99^{a}$ & $1,44 \pm 0,52^{\mathrm{a}}$ & $1,83 \pm 1,78^{a}$ & $2,84 \pm 1,40^{a}$ & $3,49 \pm 1,86^{a}$ & $8,84 \pm 8,06^{b}$ & $5,52 \pm 7,98^{c, y}$ \\
\hline \multicolumn{12}{|c|}{$6 \mathrm{~mm}$} \\
\hline Deep-fat & $75,74 \pm 8,23^{d}$ & $4,51 \pm 2,32^{a, y}$ & $4,44 \pm 1,95^{a, y}$ & $4,23 \pm 1,32^{a, y}$ & $3,84 \pm 2,30^{a, y}$ & $4,76 \pm 1,77^{a, y}$ & $7,48 \pm 3,93^{a}$ & $5,51 \pm 3,61^{a, y}$ & $5,71 \pm 2,05^{a}$ & $30,92 \pm 22,56^{b}$ & $50,83 \pm 26,76^{c}$ \\
\hline Air & $75,74 \pm 8,23^{c}$ & $29,24 \pm 11,95^{\mathrm{b}, \mathrm{z}}$ & $7,46 \pm 1,70^{a, z}$ & $7,29 \pm 3,20^{a, z}$ & $8,27 \pm 3,67^{a, z}$ & $8,95 \pm 3,47^{a, z}$ & $8,07 \pm 4,09^{a}$ & $11,49 \pm 3,04^{\mathrm{a}, \mathrm{z}}$ & $10,59 \pm 5,85^{a}$ & $27,73 \pm 16,19^{b}$ & $29,72 \pm 16,46^{b}$ \\
\hline
\end{tabular}


Table 2- Quantitative descriptive analysis of French fries in both types processes: Deep-fat (9 526 minutes) and Air (21 minutes) frying.

\begin{tabular}{|c|c|c|c|c|}
\hline & & Deep-fat frying & Air frying & \\
\hline \multicolumn{5}{|l|}{ Appearance } \\
\hline & Brown & $10,85 \pm 6,33^{a}$ & $8,33 \pm 7,83^{a}$ & ns \\
\hline & Puffed & $42,45 \pm 15,84^{a}$ & $1,00 \pm 3,16^{b}$ & $* * *$ \\
\hline & Dryness & $62,95 \pm 15,21^{a}$ & $29,08 \pm 17,74^{b}$ & $* * *$ \\
\hline & Evenness of Cook & $48,93 \pm 16,83^{a}$ & $54,45 \pm 15,15^{a}$ & ns \\
\hline & Oil release to fingers & $0,50 \pm 0,99^{b}$ & $41,55 \pm 16,38^{a}$ & $* * *$ \\
\hline \multicolumn{5}{|l|}{ Odor } \\
\hline & Jacket Potato & $43,10 \pm 12,66^{a}$ & $1,08 \pm 3,40^{b}$ & $* * *$ \\
\hline & Boiled Potato & $5,33 \pm 7,70^{b}$ & $18,83 \pm 5,72^{\mathrm{a}}$ & $* *$ \\
\hline & Fried Odour & $2,55 \pm 8,06^{b}$ & $40,63 \pm 11,84^{a}$ & $* * *$ \\
\hline & Old Fat & $2,00 \pm 6,32^{a}$ & $1,38 \pm 3,36^{a}$ & ns \\
\hline \multicolumn{5}{|l|}{ Mouthfeel } \\
\hline & Smoothness of Outer Skin & $55,73 \pm 18,40^{a}$ & $31,80 \pm 18,39^{b}$ & $* *$ \\
\hline & Toughness of Outer Skin & $48,40 \pm 16,70^{a}$ & $22,73 \pm 11,00^{b}$ & $* * *$ \\
\hline & Crispness of Outer Skin & $39,58 \pm 23,68^{a}$ & $36,55 \pm 14,11^{\mathrm{a}}$ & ns \\
\hline & Dessicated & $58,70 \pm 14,31^{\mathrm{a}}$ & $20,75 \pm 16,92^{b}$ & $* * *$ \\
\hline & Oily mouthfeel & $1,80 \pm 4,65^{b}$ & $26,83 \pm 11,09^{a}$ & $* * *$ \\
\hline & Hollow Gap 1/2 & $1,05 \pm 0,16^{b}$ & $2,00 \pm 0,00^{a}$ & $* * *$ \\
\hline & Moistness of Core Potato & $15,93 \pm 8,53^{b}$ & $28,88 \pm 11,65^{a}$ & $*$ \\
\hline & Chewy & $42,30 \pm 14,42^{a}$ & $21,58 \pm 13,23^{b}$ & $* * *$ \\
\hline & Dense & $22,98 \pm 12,28^{a}$ & $31,63 \pm 14,52^{a}$ & ns \\
\hline & Amount of potato inside & $24,20 \pm 13,72^{b}$ & $54,60 \pm 20,04^{a}$ & $* * *$ \\
\hline & Floury & $9,15 \pm 8,14^{b}$ & $34,05 \pm 19,44^{a}$ & $* *$ \\
\hline \multicolumn{5}{|l|}{ Taste } \\
\hline & Sweet & $11,68 \pm 11,04^{b}$ & $19,33 \pm 6,60^{a}$ & $*$ \\
\hline & Acidic & $4,60 \pm 7,04^{a}$ & $3,75 \pm 5,58^{a}$ & ns \\
\hline \multicolumn{5}{|l|}{ Flavour } \\
\hline & Oily Flavour & $2,10 \pm 5,59^{b}$ & $26,38 \pm 8,38^{a}$ & $* * *$ \\
\hline & Jacket Potato Flavour & $40,55 \pm 19,07^{a}$ & $0,63 \pm 1,98^{b}$ & $* * *$ \\
\hline & Boiled Potato & $6,80 \pm 10,52^{b}$ & $21,28 \pm 7,65^{\mathrm{a}}$ & $*$ \\
\hline & Earthy & $7,35 \pm 8,69^{\text {a }}$ & $0,60 \pm 1,90^{b}$ & $*$ \\
\hline \multicolumn{5}{|l|}{ After Effects } \\
\hline & Bitter & $9,05 \pm 8,12^{a}$ & $3,70 \pm 4,11^{\mathrm{a}}$ & ns \\
\hline & Metallic & $0,25 \pm 0,79^{a}$ & $0,00 \pm 0,00^{a}$ & ns \\
\hline & Acidic & $3,78 \pm 7,67^{a}$ & $2,60 \pm 3,51^{\mathrm{a}}$ & ns \\
\hline & Oily film coating mouth & $1,20 \pm 3,71^{b}$ & $17,73 \pm 7,17^{a}$ & $* * *$ \\
\hline & Greasy Fingers & $0,53 \pm 1,11^{b}$ & $33,88 \pm 16,53^{a}$ & $* * *$ \\
\hline
\end{tabular}


Figure 1- Schematic representation of air fryer: (a) fan, (b) electrical resistance heater, (c) hot air and (d) samples. It may be noted that there are a variety of proprietary hardware designs available each claiming heat and mass transport advantages as well as improved product quality, for instance, see Erickson (1989). 


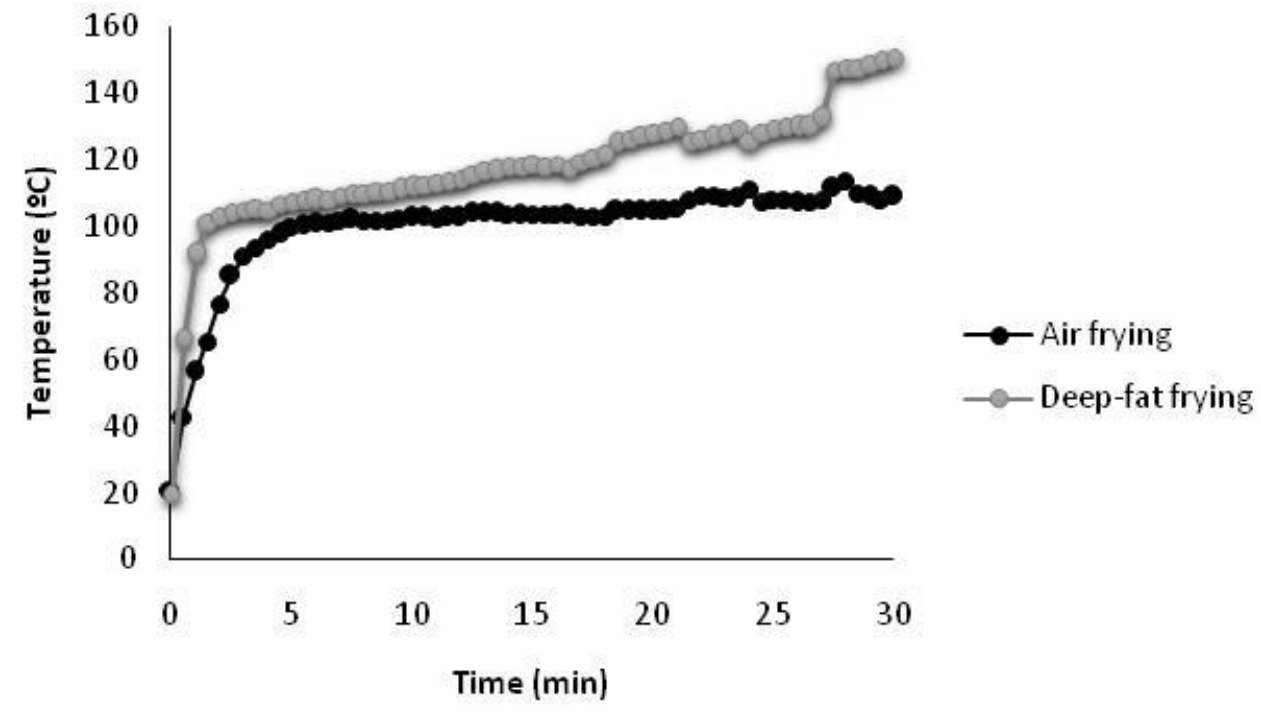

550

551 Figure 2- Evolution of Temperature inside French fries in both types processes at $1800^{\circ} \mathrm{C}$, 552 deep-fat and air frying. Both sets of experiments were performed in triplicate and the 553 temperatures shown are mean values.

554

555

556

557

558

559

560

561

562

563

564

565

566 


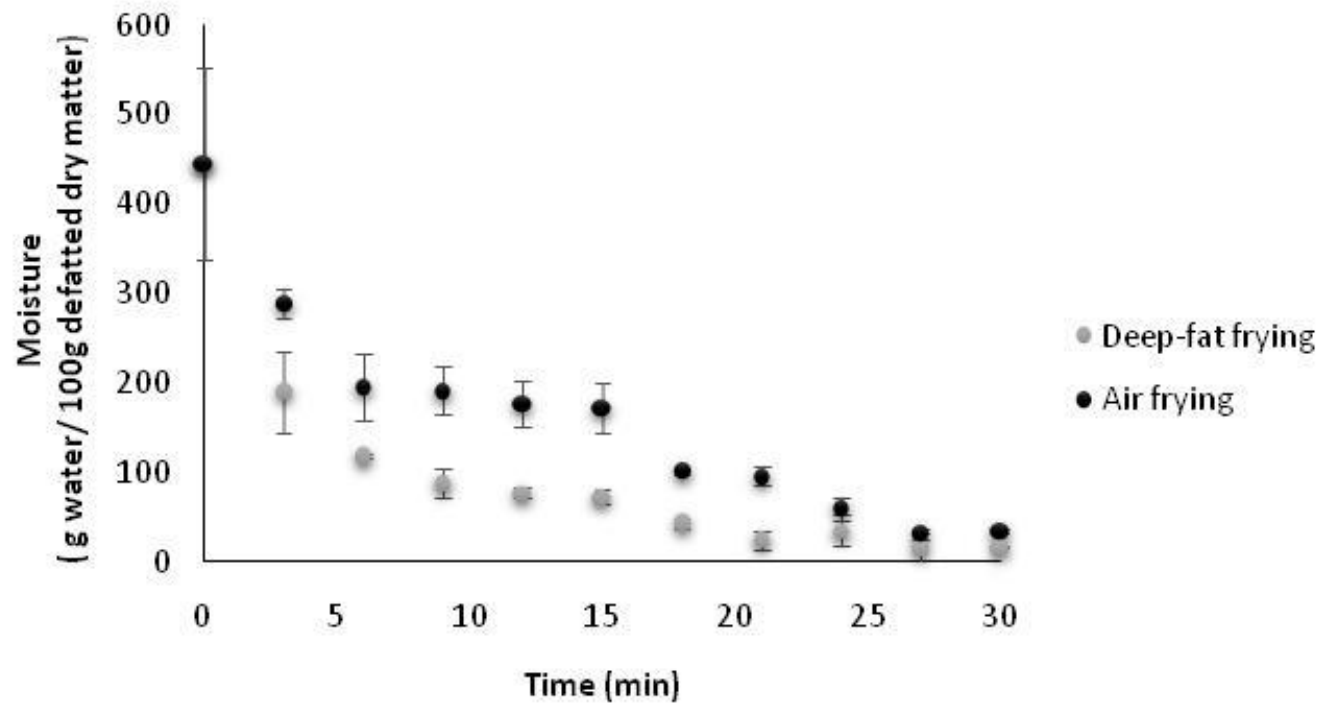

569 Figure 3- Evolution of moisture values of French fries in both types processes at 180ㄷ, deep-

570 fat and air frying. Data shown in the figure are based on experiments performed in 571 triplicates.

572 


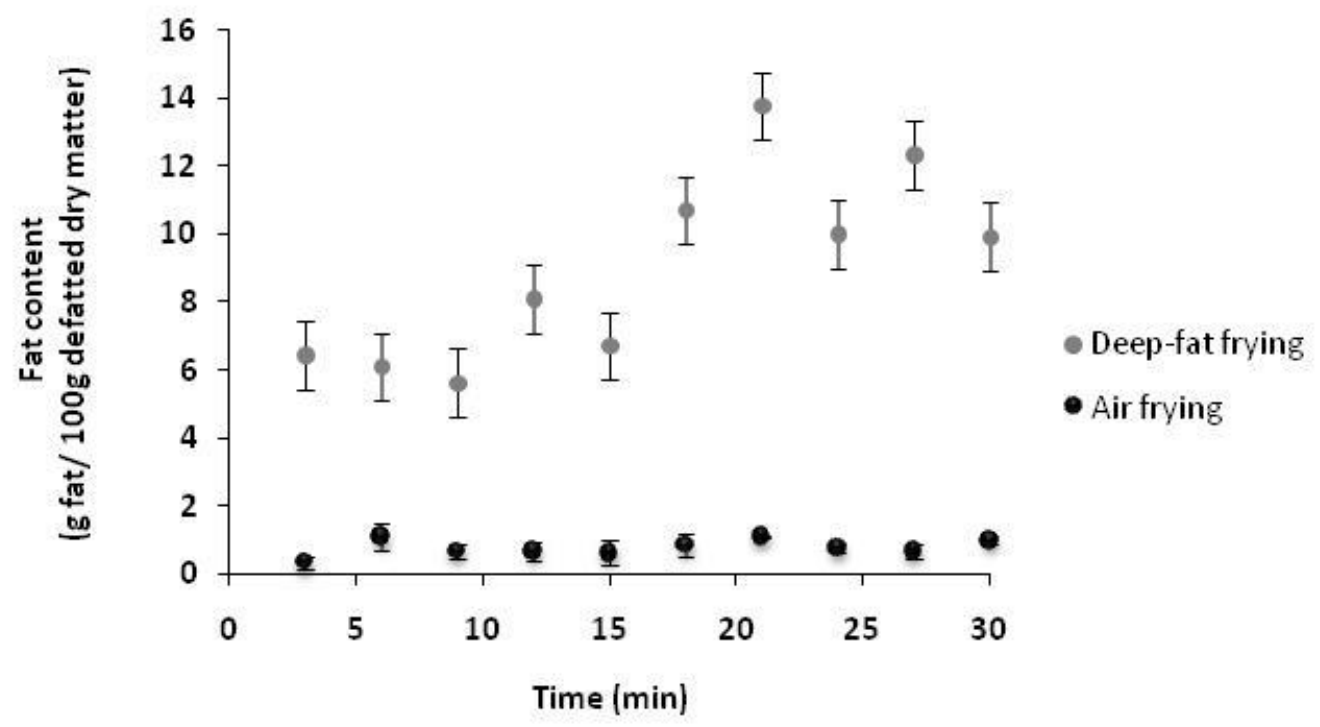

582 Figure 4- Evolution of fat values of French fries in both types processes at 180C, deep-fat 583 and air frying. Data shown in the figure are based on experiments performed in triplicates. 


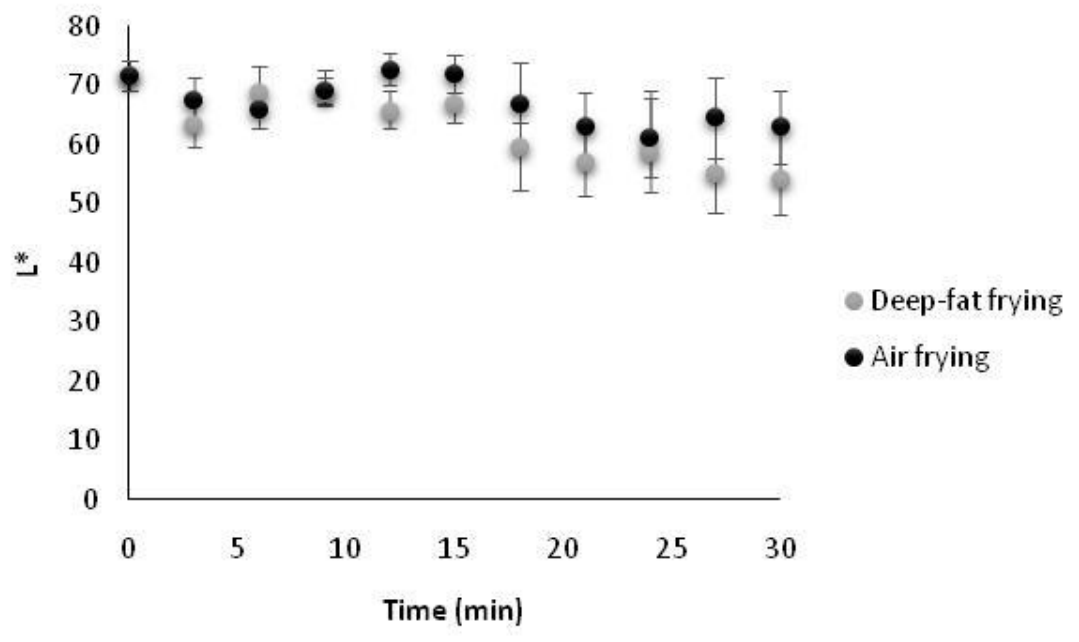

599

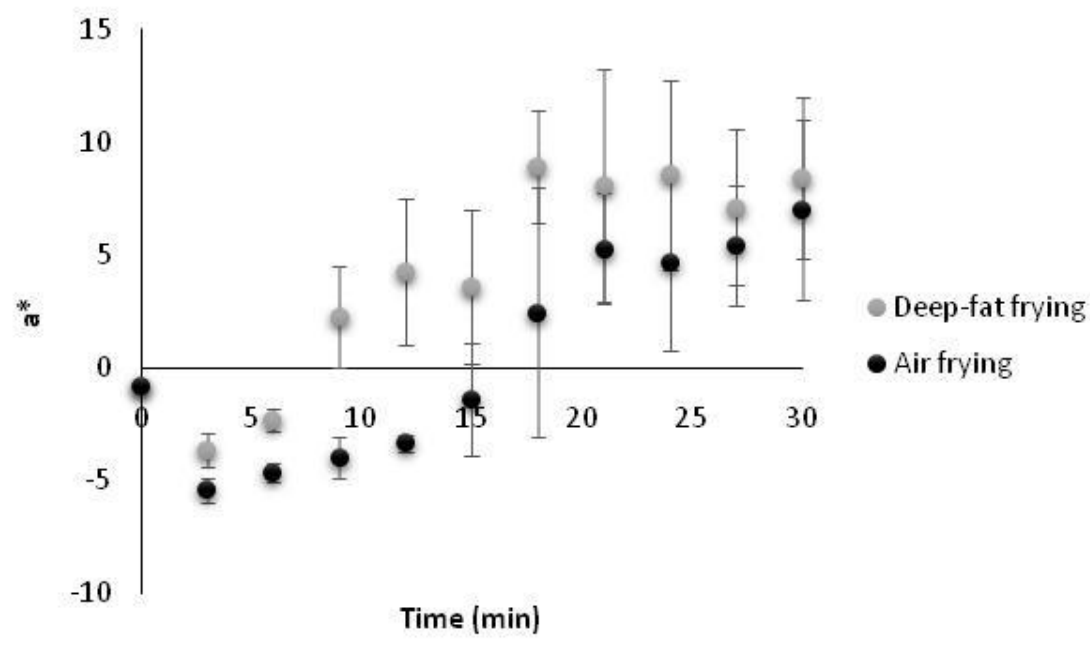

600

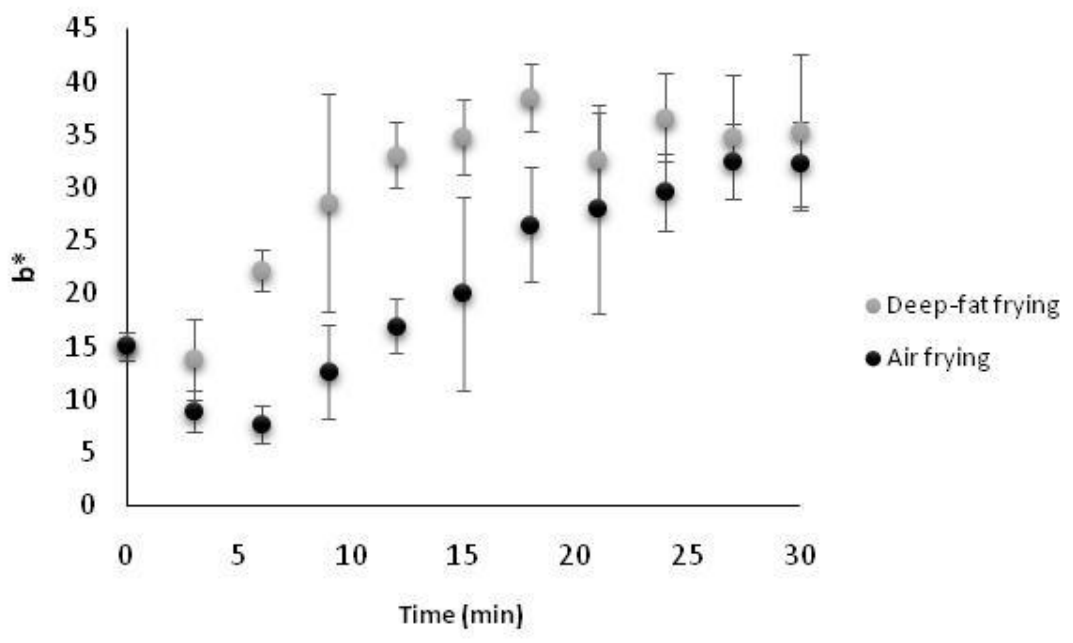

601

602

603
Figure 5- Evolution of $L^{*} a * b *$ values of French fries in both types processes at 180 -C, deepfat and air frying: $L^{*}$ values, $a *$ values, and $b *$ values. 

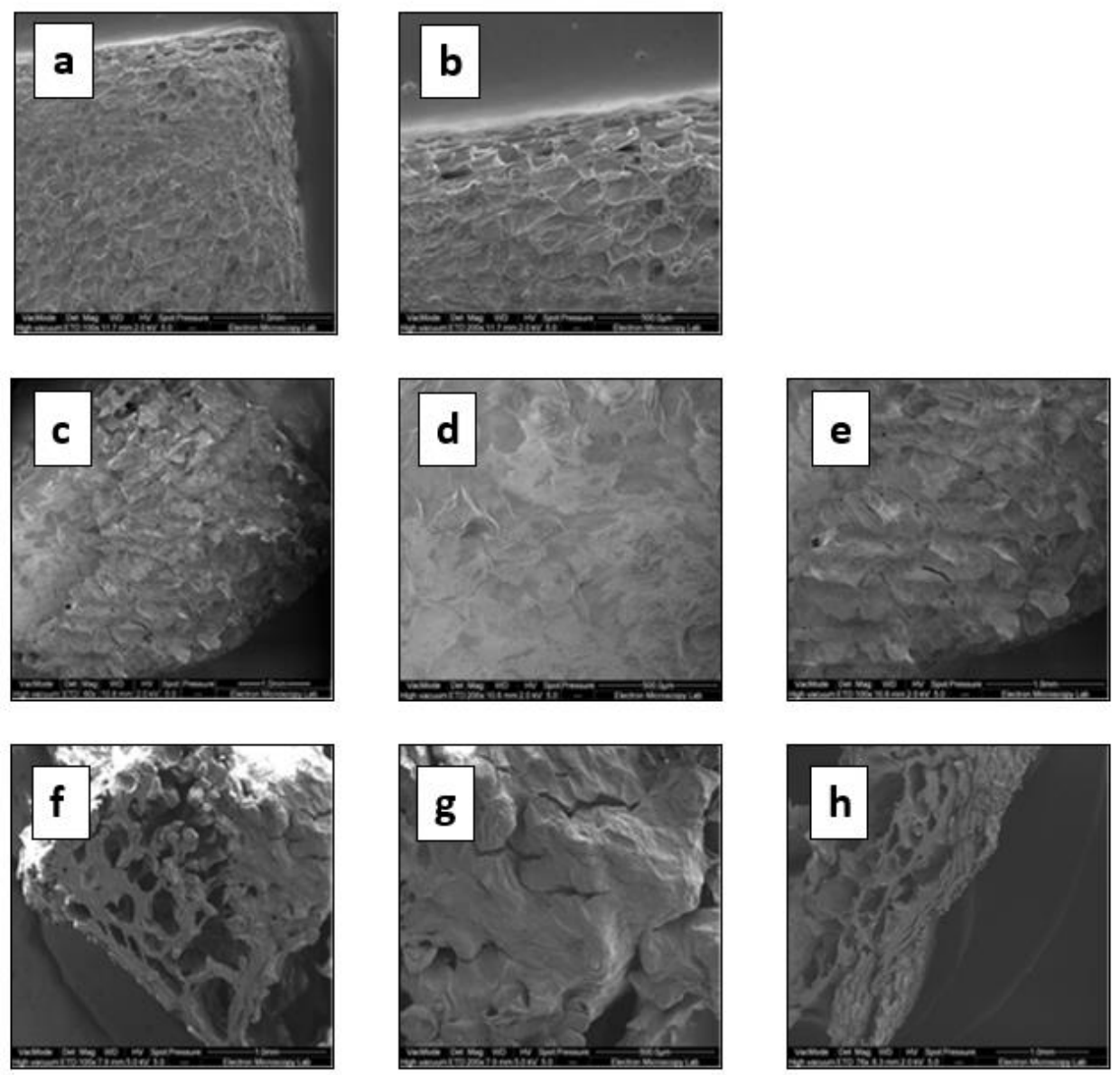

Figure 6- SEM of French fries raw, deep-fat fried (9 minutes) and air fried (21 minutes); moisture content of both samples 91.7 $\pm 6.03 \mathrm{~g}$ water/ $100 \mathrm{~g}$ defatted dry matter: (a-b) raw, (c-d-e) deep-fat fried samples, and (f-g-h) air fried samples. Figures a-c-f: sample size = 1mm; Figures b-d-g: sample size 500 ?m; Figures e-h: sample size $1 \mathrm{~mm}$. 


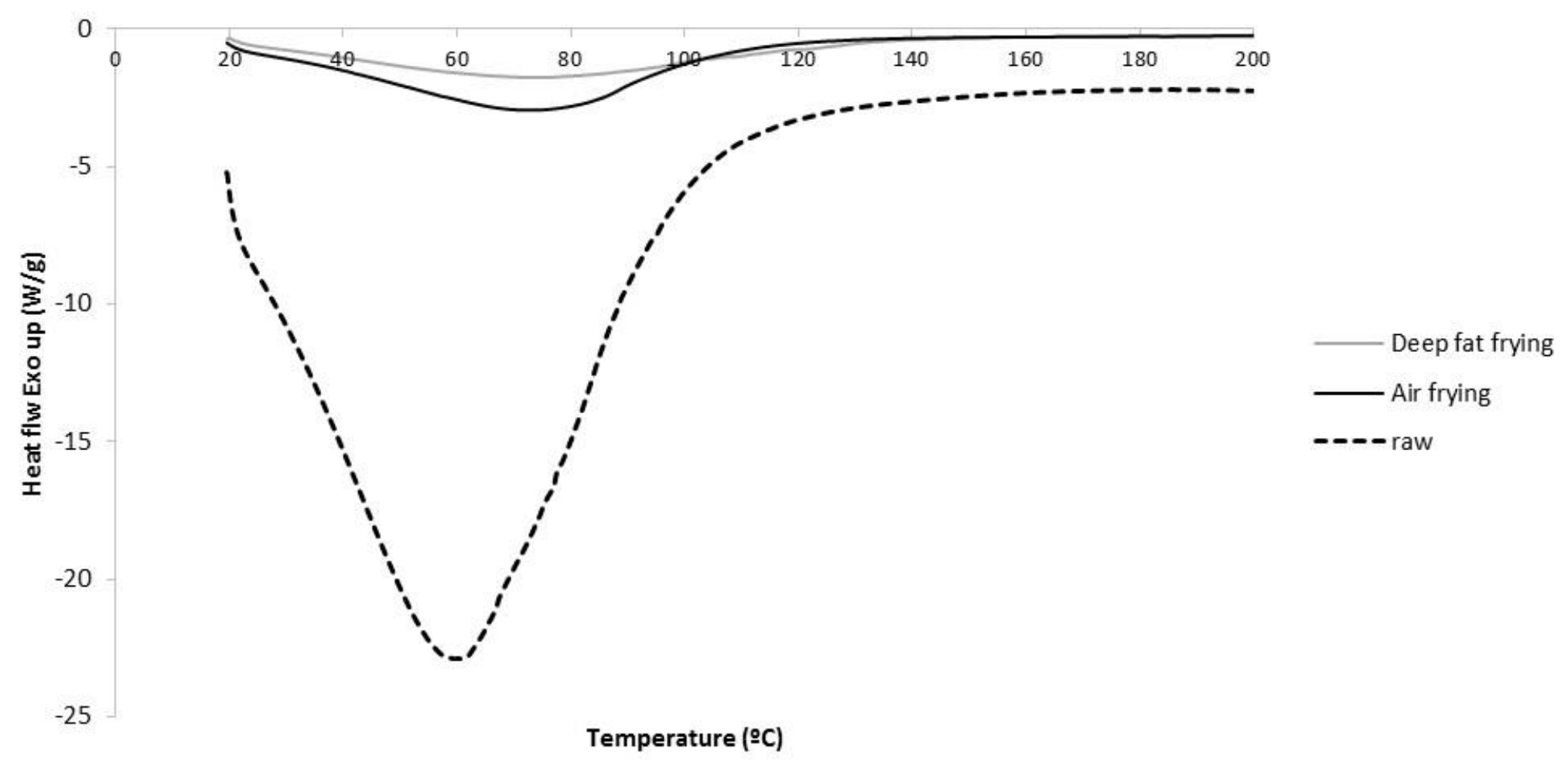

Figure 7- Gelatinization endotherms of French fries: raw samples, deep-fat frying samples (9 minutes) and air frying samples (21 minutes) ); moisture content of both samples $91.7 \pm 6.03 \mathrm{~g}$ water/ $100 \mathrm{~g}$ defatted dry matter. 


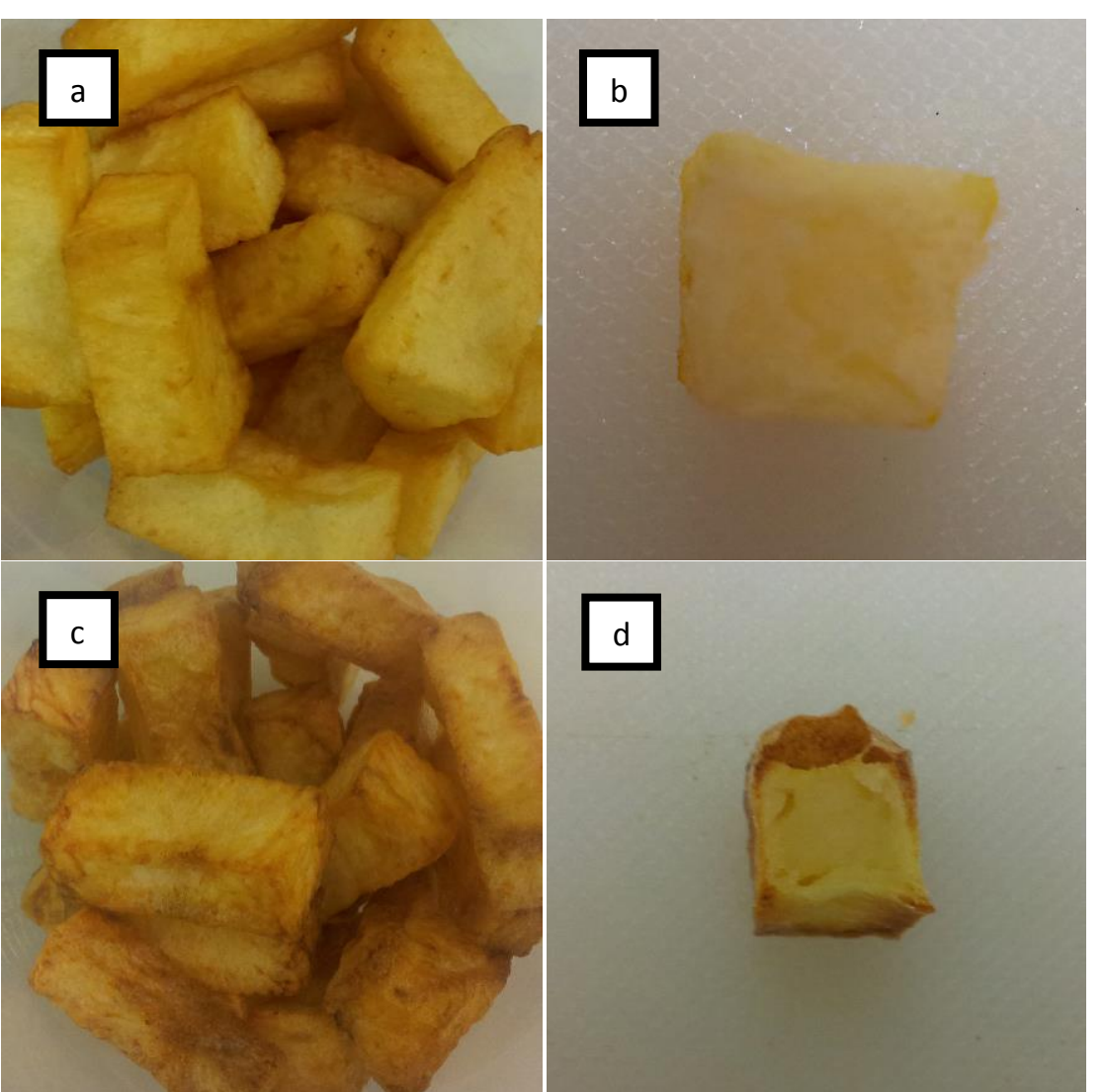

624 Figure 8- Pictures of French fries samples: deep-fat for 9 minutes (a-b) and air for 21 minutes (b-c) ); moisture content of both

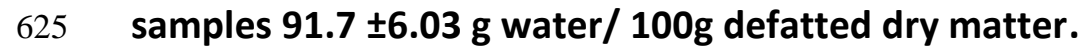

